\title{
Discussing dialogue: perspectives on the value of science dialogue events that do not inform policy
}

\author{
Sarah Davies, Ellen McCallie, Elin Simonsson, Jane L. Lehr and \\ Sally Duensing
}

While theoretical work and empirical research have examined science policyinforming "dialogue events," dialogue events that do not seek to inform public policy are under-theorized and under-researched, even though they are common and growing in popularity in the UK. We describe how, from a critical perspective, it may initially appear that such events cannot be justified without returning to the deficit model. But with this paper, we seek to open up a discussion about these non policy-informing events by arguing that there are in fact further ways to understand and frame them. We deliberately draw on different literatures and seek to make use of practitioner expertise within our discussion, in order to display several perspectives on the value of non-policy dialogue on science as sites of symmetrical individual or small-scale learning — rather than institutional learning—-through social processes.

\section{Introduction}

Over the last decade within the UK,1 government and philanthropic organizations have been actively promoting many forms of public engagement with science (British Association for the Advancement of Science, 1999; Council for Science and Technology, 2005; Parliamentary Office of Science and Technology, 2001, 2006; Royal Society, 1999). The Science and Society Third Report (House of Lords Select Committee, 2000) can be seen as having solidified this trend towards science-society communication being based on a "dialogue" rather than a “deficit model” (Wynne, 2005).

The familiar concept of a deficit model of the public was coined by Wynne in the late 1980s (Irwin and Wynne, 1996; Wynne, 1992a, 1993) to describe the implicit assumptions within science itself and much of the then burgeoning "public understanding of science" (PUS) movement. The model depicts the public above all as deficient: in knowledge, understanding, and agency. In the context of the early PUS movement, "the public" was viewed as an empty vessel, an audience waiting to be filled with a collection of authoritative scientific “facts" (Gregory and Miller, 1998).

Those who identified the deficit model also critiqued it. Research showed that publics' relations with science were much more complex than the deficit model suggested: individuals were active in handling scientific information, rather than passive; had their own forms of expertise which they applied to scientific knowledge; and-perhaps most importantly-interacted with science not in a vacuum but within social contexts and for social purposes (Layton et al., 1993; Michael, 1992, 1998; Wynne, 1992b). These studies demonstrated that, far from being simply an empty space defined only by a knowledge deficit, publics are sophisticated at handling science and at negotiating relations with it, constructing their own meanings from science communication (de Cheveigné and Véron, 1996; Wynne, 1993; Yearley, 1999).

Such findings led strongly to arguments that publics can be trusted in their dealings with science. Various authors have argued that laypeople have the competences necessary to be involved with scientific decision-making (Irwin, 2004; Kerr et al., 1998; Lévy -Leblond, 1992; Locke, 1999) and should be involved. Indeed, it can be argued that not only are the public competent to take scientific policy decisions, but that their involvement will actually help make more robust judgments (Grove-White et al., 2000; MacMillan, 2004).

These arguments provided part of the impetus for a change within the PUS movement, from a deficit model approach towards a more interactive model. Drawing on the Third Report's call for a "new mood for dialogue” (House of Lords Select Committee, 2000: 37), 
this new model stressed a "dialogue" approach in which the interactions between science and publics are mutually informing, or symmetrical. Numerous event formats have since been developed and used (for example: consultations on a national level, consultations at a local level, deliberative polling, standing consultative panels, focus groups, citizens' juries, consensus conferences, stakeholder dialogues, Internet dialogues—see Rowe and Frewer, 2005) with the aim of engaging the public with science and the specific intention of informing policy processes. Rowe and Frewer (2005) attempt to categorize these different methods based on situation and output. In practice, however, despite the diversity of formats, many of these formats are generically known as "dialogue” or "dialogue events" by practitioners.

Simultaneously, organizations—such as scientific associations and societies, science centers and museums - with no formal science and technology policy remit and no connections to scientific governance began using language such as "participation," "engagement" and "science and society." 2 They also started hosting "dialogue" or "dialogue events," but without any connection to policy. Thus, though initially developed in contexts of governance and policy processes, the language of engagement and dialogue was adopted by other institutions and implemented in a variety of ways. In this paper we therefore start with a basic typology: the premise that there are two main types of public engagement with science and technology events, those that seek to directly influence policy processes and those that do not (Lehr et al., in press). Within both types, there are events, often called dialogue events by practitioners, which claim to promote dialogue between science and publics. While this typology is simplistic, the distinctionwe would argue - is an important one and a fruitful way of analyzing "dialogue.” 3 More detailed typologies of science-society communication and dialogue are already in existence (see Bucchi and Neresini, in press; Callon, 1999; Lehr et al., in press; Rowe and Frewer, 2000, 2004, 2005).

An example of this latter type of "dialogue"-public engagement without formal connections to policy — is the events that take place at the Dana Centre, London. The Dana Centre is a venue, institutionally attached to London's Science Museum, which hosts a range of face-toface evening programs targeted toward adults and dealing with topic-areas related to science, technology and medicine. Dana Centre events are often —although not solely_based on a dialogue focused format. The main aim for these events is to produce dialogue (Science Museum Visitor Research Group, 2004; Simonsson, 2006) and to achieve this, the Dana Centre employs a range of different formats that are made up of elements that have been found to promote dialogue (McCallie et al., in review). For example, some events use a small discussion group format.

Other factors that encourage dialogue include making sure that the format, subject and aims of the event are clearly explained to participants, and providing a relaxed and friendly

atmosphere. It is also important that sufficient time for dialogue to develop is given within the event structure and that the event facilitator is skilled in promoting and supporting dialogue during the event (Simonsson, 2006).

Another key example of this second type of "dialogue" is the Café Scientifique movement (see Café Scientifique, 2006; Lehr et al., in press). First formally established in the UK, but now present in various forms around the world, "science cafés" provide for the discussion of contemporary issues in science and technology in a relaxed and informal environment. Such cafés are held in non-academic contexts and are "committed to promoting public engagement with science and to making science accountable” (Café Scientifique, 2006).4

While there is therefore a coherence of language which seems to mark a distinct trend towards "dialogue" within current relations between science and society in the UK, there remains a multiplicity of meanings of this word in use in both policy-informing and nonpolicy

related context. "Dialogue events" in a non-policy context can, from our experience, involve anything from small discussion groups to more traditional question and answer sessions. A universal definition of what constitutes a dialogue event is lacking both theoretically and within the communities that host such events.

\section{Theorizing and analyzing "dialogue": from large to small scale}

Most academic analyses of dialogue events have focused on participatory processes with direct links to policy. Such analyses have so far tended to be pessimistic (Grove-White, 
2001; Irwin, 2001; Wynne, 2001, 2002, 2005). Wynne has argued that the imposition of a naïve sociology — which includes "arbitrary, deeply inadequate and damaging visions of the human” (Wynne, 2001: 475)—which occurs in normal interactions between science and its publics is simply heightened in participatory processes. Such processes continue to be framed by science and on scientific terms, failing to take into account broader questions and different kinds of knowledge. In practice this has led to a focus on "back-end" consequences such as risk, in effect protecting the broader trajectory of scientific and technological development from accountability. Similarly, Irwin has argued in his analysis of one participatory process (Irwin, 2001) that publics were framed and positioned in negative ways by the policymakers and scientists organizing the process. A lingering deficit model perspective meant that citizens were framed as ignorant and that informing them became a key aim of the process. On a more pragmatic level, processes such as the GM Nation? debate have been criticized for their lack of clear outcomes (Rowe et al., 2005). If such debates are unfocused as to what their output should be, or fail to act on public opinion, then they leave themselves open to the charge that they are simply a public relations campaign for science, seeking to convince the public of the justification for an already-decided policy (Beder, 1999).

While there has been a small amount of other discussion examining the importance and efficacy of policy-informing dialogue events (Durodié, 2003; Jackson et al., 2005; Llewellyn, 2005; Rowe et al., 2005), dialogue events that do not seek to inform public policy are undertheorized and under-researched in regard to their nature and effectiveness, even though they are common and growing in popularity in both the UK and US.

This lack of academic research is perhaps understandable, given that the key reason for the development of public dialogue on science revolved around using public expertise to inform policy and increase democratic participation. If the goal is to have publics impact on science, why study processes that don't directly address such change? A justifiable focus on policy and effective public involvement in science has thus led to an emphasis, in analysis, on the largescale processes of science-society dialogue.

It also seems probable that the criticisms concerning the deficit model approach to engagement outlined above would be redoubled at dialogue formats that are not linked to policy processes. If policy-related dialogue has been accused of being a smokescreen for continued deficit model perspectives as well as a cynical bid to increase public trust without increasing public accountability, then what else can non-policy related dialogue events be? It appears as though dialogue events that do not directly inform policy processes simply cannot be justified, even in theory, without returning to the desire to "educate" publics or for public relations work to increase trust and acceptance. Dialogue without policy outcomes cannot, it seems, fit into an existing critical framework.

While sympathetic to this perspective, we do not simply want to abandon what is a growing phenomenon as a site of theoretical interest and empirical research. Within this paper we argue that there are other ways of understanding, valuing and framing dialogue events that do not seek to influence science policy processes. Specifically we argue three points with respect to the interest in and value of such events. First, we argue that a shift in perspective to analyzing dialogue on the level of individuals and small groups, rather than that of institutions (governments, publics, organizations), removes many of the problems of a lack of policy outcomes by focusing attention on outcomes on a much smaller scale. Dialogue events can thus be viewed as sites of individual learning through social processes.5 Second, we claim that dialogue events that do not seek to inform policy do not have to be based on a deficit model of interaction between scientists and publics, and we support this by emphasizing the importance of symmetry in learning. Third, we discuss learning as more than an accumulation of facts: learning involves emotions, empathy, and social understandings. In doing this, we are careful to distance ourselves from the model of learning present in PUS, in which the end goal was dependent upon participants memorizing and mastering the material presented by the “experts" (referred to as a "transmission-and-acquisition” model, Sawyer, 2006). The model of learning we discuss views understandings and learning as created, directed, and determined by those participating. We conclude that by focusing on these concepts, dialogue events that do not seek to influence 
policy could (1) provide opportunities for empowering individuals for further involvement, (2) be viewed as personally beneficial, or (3) be part of a gradual step by step change in science and society.

Thus this paper opens up a discussion about non-policy informing dialogue events. We are deliberately drawing on research from more than one literature base-in particular education and public participation literature- and have sought to make use of practitioner expertise within our discussion. We are therefore seeking to display several perspectives on the value of non-policy dialogue on science-which, indeed, no one theoretical perspective can claim as its own domain. While each approach can be critiqued (in ways that themselves depend on one's own theoretical standpoint), we largely leave this to the reader. Our aim is to provide a richness of outlook that mirrors the process of dialogue itself in its articulation of several worlds.

\section{Dialogue as a symmetrical learning process: views from participatory and educational literature}

The focus on individual benefit within dialogue processes is not a new concept within public participation literature. Laird (1993), for example, has argued that learning is a useful outcome of participatory processes. In his discussion of direct participation in democratic processes he describes how "educational and psychological effects" (Laird, 1993: 345) on participants are viewed as a useful outcome alongside actual effects on policy. As he writes, "democracy enables people to become fully developed citizens" (p. 345). Such learning is not merely of new "facts," but rather is an augmented understanding of the complexity of an issue, the wide range of views, and the various ways to negotiate and analyze these. The idea of "social learning" is perhaps useful to us here (Limoges, 1993; Rip, 1986). Developed in the context of scientific controversies in the public domain, the concept of social learning describes a process of articulation of different viewpoints and the interactions of these viewpoints. Limoges suggests that to maximize social learning, controversies should be managed in order to ensure the articulation of as many different viewpoints or "worlds of relevance" as possible. It is through this articulation, followed by the negotiation and bridging of these worlds, that learning can occur, perhaps changing the very nature of the controversy in the process. Importantly, this learning "is not a question of transferring existing knowledge, understanding or skills to people who do not yet master them. The learning is open ended ... The controversy is about what the content of the learning should be” (Rip, 1986: 358). There is therefore no fixed agenda, no one set of facts to be transmitted from one group to another. Debate will focus around which issues are important as much as the content of those issues.

In the context of controversies, there is a clear endpoint to be aimed for: a socially robust outcome, 6 which Limoges and Rip argue can be best reached through this process of social learning. The scale again tends to be on the level of institutions and the learning on the level of whole societies. But the concept can also be applied on a smaller scale to those individuals within dialogue processes. As articulation occurs within these contexts, diverse-indeed, often incommensurable - worlds are described and understood and negotiated. The learning that takes place would not be only or even primarily expected to be about new "facts" or information; rather it would be a complex process of social, cultural and moral understanding and may result in changes of attitude as well as of knowledge and knowledge of knowledge.

Similar conceptualizations of learning appear within the educational literature. For example Cremin (1988: x) recognizes education as "the deliberate, systematic and sustained effort to transmit, evoke, or acquire knowledge, values, attitudes, skills and sensibilities, as well as any learning that results from that effort, direct or indirect, intended or unintended.” This definition reformulates education from a one-way, transmission process solely concerned about the acquisition of facts (Sawyer, 2006; Silberman, 1970) to a powerful conceptualization that provides for learning to take place (or not) when one is specifically intending to "teach" or "learn" as well as when no one intends to be teaching or learning (Lave and Wenger, 1999; Rogoff et al., 2003). Likewise, included in this definition of education are the domains of morals, ethics, attitudes, dispositions, and abilities to successfully operate within society (cf. Kolstø 2001; Sadler and Zeidler, 2003). Education, in terms of teaching and learning, thus moves from filling an empty 
vessel to interacting with others in order to become more aware and capable people. In the case of dialogue events, the explicit mission of the event or venue may not be to "educate." However, by the nature of the social interactions promoted within the events and the intentional and unintentional learning and teaching which may be taking place, they can reasonably be considered an educational context. Thus in order to understand further the value of dialogue events from this perspective it is useful to survey some recent trends within education.

A major focus of recent science education in both the US and the UK has been "science literacy" (American Association for the Advancement of Science, 1993; Bingle and Gaskell, 1994; DeBoer, 2000), “science-for-all” (Jenkins, 2000), or “science for citizenship” (Osborne, 2000, 2002; Ratcliffe and Grace, 2003). Dialogue events fit within these science-for-citizenship aims of science education. Science-for-citizenship argues that the purpose of science education focuses on preparing citizens for life within societies in which science plays a significant role, including preparing citizens who are going to be scientists as well as those who are not. Engagement with science in the context of society allows scientists and publics to explore ideas, to examine current societal issues, to challenge the claims of others, and to develop their own understandings. Thus, whether or not dialogue events inform policy, they may provide an important and effective venue for adults to voluntarily engage with science in the context of society.7

To achieve science-for-citizenship goals, science education must move beyond "scienceasfact," in which science is presented as a static body of facts to be mastered. Instead science needs to be presented and explored as "ideas-about-science" (Millar and Osborne, 1998) in which the nature of science and the processes of science are studied in parallel with current scientific understandings (Osborne et al., 2003) and science-in-the-making (Latour, 1987). In dialogue events, the mix of those who generate scientific knowledge, those who affect its use in context, and those who experience it in daily life can bring to the fore the social, cultural, and moral aspects of science in society in order for them to be discussed transparently. In this way, dialogue events move beyond serving as a forum for transmission and acceptance of science to a place of problematizing and negotiating knowledge. 8

The science education literature also advocates a toolkit of pedagogies, depending on the nature of what is to be learned and who is learning. While Cremin's definition of education implies that learning takes place in all settings, whether intentionally or unintentionally, socio-cultural and social constructivist theories of learning argue that some types of interactions promote greater learning than other types of interactions. The overarching, common premise between these approaches is that active participation in one's learning enhances meaning-making. The two theories focus on different aspects of the interactions, however. First, socio-cultural theories of learning place prime importance on the pedagogies of social interaction and the fact that learning is mediated by cultural tools such as language (Rowe, 2004). For example, it is theorized that people come to or achieve greater, more advanced, or more complex meaning-making through talking with others in a dialogue format, especially with others with different experiences or expertise. This does not suggest that all social interaction is more productive than an individual working alone- the key is to create social interactions that facilitate achievement beyond individual capacity (Mercer, 2000; Mortimer and Scott, 2003; Vygotsky, 1978; Wells, 1999).

Social constructivist theory, however, focuses on pedagogies that support people integrating past experiences and understandings with current experiences in order to construct new understandings (Driver, 1997; Hodson and Hodson, 1998). These pedagogies encourage active participation and see all learning as constructed meaning-making. Social constructivist pedagogies often encourage people to interact in order to facilitate personal understanding, but most importantly, they directly negate the transmission model of learning. In summary, these theoretical approaches to learning about science and socio-scientific issues lead to pedagogies that encourage direct and sustained interaction amongst people. Science education, in its broadest sense, is thus inherent in dialogue events because they are social events that involve interaction and meaning-making and therefore are sites of learning. Such events can therefore be a subject of study for educationalists as well as for those interested in public participation in science, and their perspectives are both valid and valuable for understanding better the processes that occur in these events. Educationalists will—as we have 
described above—view "dialogue” as valuable in a variety of ways.

Learning — social or otherwise — can be viewed as empowering participants for further debate. But positioning learning as the key outcome for participants in non-policy dialogue, as we do, could still appear a deeply deficit model perspective. It is therefore vital that any such learning, to be truly part of a dialogue process, should be symmetrical. Social learning and enhanced understandings must occur within all those involved, whether they are present in their roles as scientists or as citizens. Rogoff, Matusov and White (1996) specifically describe this type of learning and teaching as based on a socio-cultural model in which no one participant has a fixed role, each has an active role in learning among the community, and the roles one takes will change over time, such that participants will experience various roles at different times and in reference to different issues.

Thus the dialogue forum should not imply the superiority of one form of knowledge over others or the expertise of one group as more valuable than that of others: conditions of strict equality must be imposed. The dialogue would then be occurring on a micro scale; rather than public(s) interacting with science(s) en masse to influence policy and knowledge production, individuals would interact with other individuals to come to shared understandings in the processes of learning described above. Impacts and outcomes will be on the level of individuals and could be anything from changed knowledges, understandings or attitudes to changed behavior. As Laird notes for direct participation theory, participation "changes the outlooks and attitudes of participants. It makes people more aware of the linkages between public and private interests, helps them develop a sense of justice, and is a critical part of the process of developing a sense of community" (Laird, 1993: 345). In other words, social learning in a dialogue forum could equip all involved to be more effective citizens.

Indeed, it could be argued that non-policy dialogue may in some ways be a better forum for this learning process than dialogue with policy outputs, where formalized, consensual outcomes are often demanded. Without the reductionist pressure of having to create an often impossible consensus or sum up diverse viewpoints into one statement or recommendation, participants can be free to explore all positions and to avoid polarizing the debate into opposing camps. As Rip (1986) discusses, such processes, in all their complexity, tend to lead to a more socially robust outcome to a controversy. Non-policy dialogue could therefore be viewed as a part of, and in fact linked to, wider and more formal interactions between science and society: dialogical processes, in their development of citizens, could empower and equip individuals and small groups. Media attention may bring the diverse articulations of the issues at stake further into the public sphere. If managed correctly (see Limoges, 1993), dialogue events around controversial issues could initiate a "ripple" effect of activity, protest, and participation which leads to policy impacts.9

\section{Dialogue in practice: the value of dialogue events that do not inform policy from a museum's perspective}

We now turn to look at the value of dialogue events that do not aim to influence policymaking from a practitioner's perspective-specifically, from the experience of one of the authors in working with the Science Museum's Dana Centre in London. We have already discussed some of the details of the format and process of Dana Centre events. As museums and other informal institutions have no remit to influence science policy directly, the dialogue processes they are involved in rarely have formal policy outputs. However, such institutions see dialogic processes as valuable and useful to them: it is this perspective, and the reasoning behind it, that we explore here.

We have already pointed out that there are currently many varying meanings of what dialogue is and what it involves. One such meaning is the Dana Centre's definition: dialogue is a process of communication in which two or more participants engage in an open exploration of issues and relationships on an equitable basis. Dialogue is the exchange of ideas, opinions, beliefs, and feelings between participants-both speakers and audience. It is listening with respect to others and being able to express one's own views with confidence. 
Dialogue is not silence, chaos, or one person or faction monopolizing the session.

(Gammon and Burch, 2003: 1)

This meaning is used when such events are developed, delivered and evaluated by museum staff. This definition also outlines what should happen during dialogue-focused events and highlights the importance of the interactions within these events being social and symmetrical. Thus, according to the Dana Centre, for dialogue-focused event formats to be considered successful it is important that dialogue occurs during the event and that participants take part in a two-way communication: a question and answer session could not be considered a successful dialogue event.

More specifically, the Science Museum's Dana Centre finds dialogue events valuable for a number of reasons. Firstly, events that are based on a dialogue format help the Dana Centre to achieve its aim of actively engaging people in discussions on science. This aim is also in line with a section of the vision statement of the NMSI (the National Museum of Science and Industry, the overall body of which the Dana Centre is part):

We engage people in a dialogue to create meanings from the past, present and future of human ingenuity. (NMSI, 2002: 3)

Thus, when dialogue between participants occurs during a Dana Centre event, it contributes towards NMSI achieving its overall mission.

Secondly, compared to the more traditional lecture format which is primarily one-way communication, an event format based on dialogue is more interactive and gives more participants extended opportunities to actively take part and contribute. As a result, the dialogue format has the potential to offer all participants a more entertaining and enjoyable experience. Audience research conducted at Dana Centre dialogue events supports this: both invited speakers and visiting participants indicate they enjoy and prefer the dialogue-based format to the more traditional lecture set-up. In fact, even though many participants indicate they had expected the event to be a lecture-style format, they were positively surprised. The event was much more interactive and informal than they had anticipated.

I thought a lecture is a lecture, but this is actually better, it's much more interactive. (Interview with visiting participants)

A refreshing change from a stagnant lecture theatre. (Interview with visiting participant) Thirdly, the dialogue event format has the potential to promote many different types of learning. The way in which dialogue events are set up allows extended opportunities for those taking part to engage in discussions with other participants (both invited speakers and visiting participants). This is particularly true in comparison with event formats that are structured as a formal one-way communication with few opportunities to contribute and interact with others participating in the same event. Therefore, an event format that is focused on dialogue is more likely to facilitate social learning and has the potential to challenge and change participants' attitudes and opinions as ideas are discussed and negotiated. Moreover, although focused on a dialogue format, these Dana Centre events also facilitate cognitive audience research supports the need for providing participants with information relating to the topic-area under discussion. Participants want to learn. Therefore they want and expect information to be presented during the event, and when this is not given to them they are frequently disappointed. Such information does not just involve presenting factual information but also includes a variety of opinions, beliefs and ideas related to a specific topic. Dialogue events must also provide information in order for opinions to be formed or challenged and for dialogue to take place. It appears to be difficult for those attending a dialoguefocused event to discuss the issues that the event covers if they are not given any form of introduction to the relevant subject and issues-unsurprising given that it is hard to have a discussion when the topic, major issues, and boundaries of the discussion are vague or illformed among a group.

I felt like it left me wanting a discussion, but with no information I couldn't get very far with my own thoughts and would have liked people with real inside knowledge or experience to be somehow involved. (Interview with visiting participant)

Interestingly, this seems to suggest that we cannot completely discard the concept of the presentation of information or "fact" transfer being key during these events. Publics that attend are often actively seeking specific information and are frustrated if this is not accessible. 
Thus, participants conceptualized these events as resources that can be used to equip and empower themselves for further engagement.

Finally, as discussed earlier, events that use a dialogue-based format are likely to have an impact on the individual level rather than an institutional one. As such, events that use a dialogue-based format may act as a stepping stone in motivating participants (both invited speakers and visiting participants) to further involvement. This is particularly true given that these events are more interactive and offer more opportunities for contribution and active participation. Such processes can provide a neutral ground where participants from different backgrounds can meet, exchange ideas and views, and openly explore different issues. Therefore attending a Dana Centre event may inspire and motivate participants to investigate the issues covered by an event further after taking part in an event. Attending an event that uses a dialogue format may also give all attending - both those who are invited as subject specialists and those who visit the event-increased confidence to attend other, sciencefocused dialogue events or debates as they become familiar with the format. Such a raised level of confidence could motivate and enable individuals to take part in processes that do inform policy.

It is also important to point out that practitioners are aware that dialogue does not naturally occur just because an event is labeled as a dialogue event. Unpublished research on Dana Centre dialogue events has shown, for example, that during some events invited speakers have monopolized discussions or that the interaction between invited speakers and visiting participants has never moved beyond a question and answer session. However, such research not only has detected problems and barriers but has helped to ensure that dialogue-focused events are constantly altered and improved to achieve their intended outcomes.

There are many barriers to dialogue taking place during an event, and anything from the overall structure of the event, the skills, personality and experience of the facilitator and of the invited speakers to the participants who attend may affect these. It is therefore important that dialogue events such as those held at the Dana Centre are subject to research and evaluation in order for barriers to be identified and changes to be implemented. As noted above, practitioners are often aware that the "dialogue" their institutions carry out can be problematic. In addition, it seems likely that practitioner rationales, motivations and evaluations of dialogue processes would benefit from further critical analysis. In the discussions above, for example, we find ideas of dialogue as empowerment or citizen-building; of enjoyment as key to participation; and of public desire for relevant "facts" or information. Research might productively examine and interrogate some of these concepts, both in theoretical analysis (for example, asking what kind of "citizenship" is constructed by these arguments?), and in empiricalstudies of dialogue processes (including investigating longer term impacts of these events on participants). It would be productive, for instance, to examine exactly how participants view and construct the dialogue process in order to understand more fully what it means to "enjoy" this kind of event. Do they see it primarily as entertainment, and if so, how will this affect future impacts on participants' lives? Studies such as Goven's (2006) will also push us to examine not just stated motivations and reasoning but also how the wider politicaleconomic context frames and shapes dialogue.

\section{Conclusion}

We have argued that non-policy dialogue events should be viewed as having learning outcomes at the level of individuals rather than influencing policy at the level of institutions. We also argue that it is valuable to frame and evaluate dialogue events in terms of symmetrical social learning. Thus dialogue events that do not seek to influence policy are spaces enabling individuals from potentially diverse cultures to come together, articulate positions and views, and interact in a context of genuine equality. It could even be argued that this could - theoretically — be a far more effective way of affecting the culture of science to become more personally relevant and democratically accountable than through public participation in policy. Within dialogue events genuine learning should be taking place on all sides; there should be no holding back or reliance on entrenched positions of authority. And if enough individuals within science learn about the diversity of opinions about science, the 
manifold framings of scientific questions, and the pragmatic capabilities of publics, then science as a body will slowly be changed.

However, to argue that this is how non-policy dialogue could be justified is not to say that this is what actually occurs at such dialogue events—as, indeed, we have already noted within our discussion of the practitioner's point of view. Analysis of these processes is much needed in order to identify just how much of the old PUS movement's turn to dialogue is genuine and how much is rhetoric that glazes entrenched deficit model positions. Certainly anecdotal evidence (and much of our own early stage research) suggests that many dialogue events are emphatically not the spaces of equality and symmetrical social learning that is the ideal described above. Observational data indicate that dialogue events can in fact quickly revert to traditional question and answer sessions, that events may continue to operate under assumptions of the primacy of scientific knowledge, and that the roles participants assume or have imposed upon them can damage equity. Such problems may — we suggest-be due to cultural habit, a lack of clarity among organizers, speakers and other participants with respect to the intended nature of the event, or be based on how the event is policed. Those who "facilitate," for example, may not be trained or confident in producing this style of interaction. Publics also, it appears, often continue to come to dialogue events with the expectation of learning from experts and deferring to perceived authority. At the same time, emerging research indicates that some dialogue events do achieve their intended aims (McCallie, forthcoming).

Further research on these issues needs to be conducted from all of the perspectives discussed above - by those in education, science studies and by practitioners. In particular we believe that critical perspectives, when integrated into research from all these domains, can be especially valuable. Such perspectives help us challenge the taken-for-granted assumptions and boundaries found both in practice and in academic disciplines. They would push us to ask, for example, what kind of "citizenship" are educationalists referring to when they speak of "science education for citizenship"? What are the political meanings of constructing citizenship in this way? Or they might challenge the definitions of dialogue that practitioners use. Where do these definitions come from? What assumptions underpin them? Empirically, these are also rich sites for analysis. Issues of control within dialogue seem important: how are discussions "kept on track" and who decides what that track is? How are science and nonscience distinguished and bounded? How are concepts of risk and expertise constructed and used by participants?

Several of the authors are currently analyzing and characterizing the talk that occurs during dialogue events, providing some insight into learning on a social—though small-scalelevel. However, other methods are needed to evaluate how far individual learning also takes place. For example, interviewing participants after events and following up with them over time would allow researchers to determine what participants—whether scientific or lay-take away from these events, and how their lives are affected. Future research could also address the wider context of non-policy dialogue, including its links to and impacts on policy processes and cultural change, and how particular cultural assumptions—such as what "citizenship" is-are embedded in the processes.

Finally, dialogue, as we have envisioned it, requires scientists and publics to be entering the forum with open minds and desiring to learn as much as to teach. These events require all participants to come expecting both to engage with and to treat with respect other viewpoints and ways of knowing. This does not imply that people should accept all contributions equally; on the contrary each contribution should be considered critically. But such a requirement may itself need a sea change within science and society: we have suggested that currently nonpolicy dialogue is often a difficult and problematic process. Research is needed to test this suggestion and to evaluate our model of dialogue against what happens in informal dialogue contexts. Such research will do much to clarify what actually takes place within dialogue events, and will help ultimately to ensure that barriers that limit symmetrical learning and engagement are reduced.

\section{Acknowledgements}

This material is based partially upon work supported by the National Science Foundation 
under Grant No. 0119787 to the Center for Informal Learning and Schools. Any opinions, findings, conclusions or recommendations expressed in this material are those of the authors and do not necessarily reflect the views of the National Science Foundation. One of the authors has been supported by a doctoral grant from the Arts and Humanities Research Council.

\section{Notes}

1. The situation in the US and Europe is similar but not identical. In the US "dialogue events" are not new, but the involvement of informal institutions in "dialogue events" is a more recent development (Lehr et al., in press). The differences between the countries are further compounded by the histories of the "public understanding of science" and "science literacy" movements and the differing assumptions that underpin these (Jasanoff, 2005; Lehr, 2006). In this paper, therefore, we will be focusing on the situation in the UK whilst acknowledging that there are many similarities with that in the US and, indeed, in Europe.

2. For examples see the websites of the British Association for the Advancement of Science (http://www.the-ba. net/the-ba/, accessed 4 July 2006: "Your support will allow the BA to continue its mission, from our schemes for young people of every ability, encouraging participation and excellence in science, to facilitating open debate where the social and ethical issues of science can be discussed. And everything in-between!”) or the Royal Institution (http://www.rigb.org/rimain/abouttheri/index.jsp, accessed 4 July 2006: the RI "prides itself on its reputation for engaging the public in scientific debate").

3. This typology, while helpful, can be problematic in that the distinction between the two types is not always as clear-cut as it may suggest. Both types are—as described above—ultimately part of the same cultural trend towards "engagement" and there can be overlap.

4. The Café Scientifique movement grew out of the similar Café Philosophique, which started in Paris but has spread around Europe (Spire, 1998; see also PEALS, 2007). That this type of "dialogue" format is not limited to science suggests that it is part of a broader social trend that includes other areas of knowledge and expertise.

5. There is, of course, an interesting tension between our emphasis on the individual and small groups as sites of analytical interest, and our insistence that learning is a social process. We can clarify by expanding on our use of the term "individual": we use it not in a cognitive or psychological sense but rather as a way of expressing the small scale — compared to policy or other institutional effects—of the impacts we are interested in. Thus we are not suggesting that learning itself is an "individual” thing — rather, as should be clear from later sections, we believe that learning is always a social—even dialogical—process (see Lefstein, 2006). Neither do we wish to ignore wider social processes beyond the dialogue forum itself; the media and other features of the public and private spheres will impact the interactions and effects of dialogue, and be impacted in their turn. Thus any dialogue forum is situated in a much wider web of social relations than those that we consider in this paper. Further discussion of these is beyond the scope of this article and, indeed, demands empirical work alongside theoretical consideration. Thus by talking of the individual we refer to the power of small-scale interpersonal relations and the impacts that these can have in, for example, developing citizens (cf. Laird, 1993).

6. Rip uses the term "robust" to describe the successful closing down of a controversy, where "arguments, evidence, social alignments, interests, and cultural values" (Rip, 1986: 353) interrelate and lend support to a dominant view. Examples of such successful closing downs are perhaps the public controversies over the safety of smoking or of rDNA research, where the dominant view, supported by social and scientific networks, has become received wisdom (e.g. "everyone knows that smoking is bad for you”).

7. Again, there are differences between the UK and US. In particular an emphasis on science "process" and science for citizenship has been longstanding in US education (Lehr, 2006), dating from the 1980s, while this type of curriculum — while a factor in discussion for some time, e.g. Layton (1973) — has only been developed in practice over the last decade in the UK.

8. "Science-for-citizenship" is, of course, itself not unproblematic. Zembylas (2005) has distinguished between "science-for-citizenship" and "science-for-social-justice," and Lehr (2006) has discussed the type of citizenship constructed by these curricula.

9. Envisioning non-policy dialogue in this way does, of course, relate to a previous point about the limitations of our typology: interlinkages between "policy" and "non-policy" dialogue are complex and they may not always be readily distinguishable. In particular, informal and non-policy dialogue may—in our model—have wider effects that go on to influence science policy through other channels. Conversely, policy dialogue processes may also have impacts on a small scale (as Laird, 1993, argues; see also Involve, 2005).

\section{References}

American Association for the Advancement of Science (1993) Benchmarks for Science Literacy (Project 2061). New York: Oxford University Press.

Beder, S. (1999) “Public Participation or Public Relations?,” in B. Martin (ed.) Technology and Public Participation, pp. 169-92. Wollongong: Science and Technology Studies, University of Wollongong, Australia.

Bingle, W.H. and Gaskell, P.J. (1994) "Scientific Literacy for Decision Making and the Social Construction of Scientific Knowledge,” Science Education 72: 185-201. 
British Association for the Advancement of Science (1999) Evidence to the House of Lords Select Committee on Science and Technology Inquiry into Society's Relationship with Science. URL: http://www.the-ba.net/the-ba/ CurrentIssues/ReportsandPublications/Reports/ (accessed July 2006).

Bucchi, M. and Neresini, F. (in press) "Science and Public Participation," in E. Hackett, O. Amsterdamska, M. Lynch and J. Wajcman (eds) New Handbook of Science, Technology, and Society. Cambridge, MA: MIT Press.

Café Scientifique (2006) http://www.cafescientifique.org/ (accessed January 2007). Callon, M. (1999) “The Role of Lay People in the Production and Dissemination of Scientific Knowledge,” Science, Technology and Society 4(1): 81-94.

Council for Science and Technology (2005) Policy through Dialogue: Informing Policies Based on Science and Technology. March. URL: http://www2.cst.gov.uk/cst/reports/ (accessed June 2005).

Cremin, L.A. (1988) American Education, the Metropolitan Experience, 1876-1980. New York: Harper and Row.

DeBoer, G.E. (2000) "Scientific Literacy: Another Look at its Historical and Contemporary Meanings and its Relationship to Science Education Reform,” Journal of Research in Science Teaching 37(6): 585-601.

de Cheveigné, S. and Véron, E. (1996) "Science on TV: Forms and Reception of Science Programmes on French Television,” Public Understanding of Science 5: 231-53.

Driver, R. (1997) "The Application of Science Education Theories: A Reply to Stephen P. Norris and Tone Kvernbekk,” Journal of Research in Science Teaching 34(10): 1007-18.

Durodié, B. (2003) "Limitations of Public Dialogue in Science and the Rise of New 'Experts,"” Critical Review of International Social and Political Philosophy 6(4): 82-92.

Gammon, B. and Burch, A. (2003) “Indicators of Dialogue,” unpublished Science Museum paper.

Goven, J. (2006) "Processes of Inclusion, Cultures of Calculation, Structures of Power: Scientific Citizenship and the Royal Commission on Genetic Modification,” Science, Technology and Human Values 31(5): 565-98.

Gregory, J. and Miller, S. (1998) Science in Public: Communication, Culture and Credibility. New York: Plenum Press.

Grove-White, R. (2001) “New Wine, Old Bottles? Personal Reflections on the New Biotechnology Commissions,” Political Quarterly 72(4): 466-72.

Grove-White, R., Macnaghten, P. and Wynne, B. (2000) Wising Up: The Public and New Technologies. Lancaster: Centre for the Study of Environmental Change, Lancaster University.

Hodson, D. and Hodson, J. (1998) “From Constructivism to Social Constructivism: a Vygotskian Perspective on Teaching and Learning Science,” School Science Review 29(289): 33-41

House of Lords Select Committee on Science and Technology (2000) Third Report: Science and Society. 23 February. URL: www.parliament.the-stationery-office.co.uk (accessed October 2004).

Involve (2005) People and Participation: How to Put Citizens at the Heart of Decision-making. London: Involve.

Irwin, A. (2001) “Constructing the Scientific Citizen: Science and Democracy in the Biosciences,” Public Understanding of Science 10: 1-18.

Irwin, A. (2004) "Rather than Representing Citizens as Risk-Averse, We Should be Engaging More with What People Want from Technical Change,” Spiked online debate. URL: http://www.spiked-online.com/ articles/0000000CA375.htm (accessed November 2004).

Irwin, A. and Wynne, B., eds (1996) Misunderstanding Science? The Public Reconstruction of Science and Technology. Cambridge: Cambridge University Press.

Jackson, R., Barbagallo, F. and Haste, H. (2005) “Strengths of Public Dialogue on Science-Related Issues,” Critical Review of International Social and Political Philosophy 8(3): 349-58.

Jasanoff, S. (2005) Designs on Nature: Science and Democracy in Europe and the United States. Princeton, NJ: Princeton University Press.

Jenkins, E. (2000) “'Science for All’: Time for a Paradigm Shift?,” in R. Millar, J. Leach and J. Osborne (eds) Improving Science Education, pp. 207-26. Buckingham: Open University Press.

Kerr, A., Cunningham-Burley, S. and Amos, A. (1998) “The New Genetics and Health: Mobilising Lay Expertise,” 
Public Understanding of Science 7: 41-60.

Kolstø, S.D. (2001) “To Trust or Not to Trust ... Pupils’ Ways of Judging Information Encountered in a SocioScientific Issue,” International Journal of Science Education 23: 877-901.

Laird, F.N. (1993) “Participatory Analysis, Democracy and Technological Decision Making,” Science, Technology and Human Values 18(3): 341-61.

Latour, B. (1987) Science in Action: How to Follow Scientists and Engineers through Society. Milton Keynes: Open University Press.

Lave, J. and Wenger, E. (1999) “Legitimate Peripheral Participation in Communities of Practice,” in R. McCormick and C. Paechter (eds) Learning and Knowledge. Milton Keynes: Open University Press.

Layton, D. (1973) Science for the People: The Origins of the School Science Curriculum in England. London: Allen and Unwin.

Layton, D., Jenkins, E., Macgill, S. and Davey, A. (1993) Inarticulate Science? Perspectives on the Public Understanding of Science and Some Implications for Science Education. Nafferton: Studies in Education Ltd.

Lefstein, A. (2006) Dialogue in Schools: Towards a Pragmatic Approach. Working Paper 33. London: King's College London.

Lehr, J.L. (2006) “Social Justice Pedagogies and Scientific Knowledge: Remaking Citizenship in the Non-Science Classroom," unpublished doctoral dissertation, Virginia Tech.

Lehr, J.L., McCallie, E., Davies, S.R. Caron, B.R., Gammon, B. and Duensing, S. (2007) "The Role and Value of Dialogue Events as Sites of Informal Science Learning,” International Journal of Science Education, 29(12): $1-21$.

Lévy-Leblond, J. (1992) “About Misunderstandings about Misunderstandings,” Public Understanding of Science 1: $17-21$

Limoges, C. (1993) “Expert Knowledge and Decision-Making in Controversy Contexts,” Public Understanding of Science 2: 417-26.

Llewellyn, N. (2005) “Audience Participation in Political Discourse: a Study of Public Meetings,” Sociology 9(4): 697-716.

Locke, S. (1999) “Golem Science and the Public Understanding of Science: From Deficit to Dilemma,” Public Understanding of Science 8: 75-92.

McCallie, E. (forthcoming) Ph.D. thesis, Department of Education and Professional Studies, King’s College London.

McCallie, E., Simonsson, E., Gammon, B., Nilsson, K., Lehr, J. and Davies, S.R. (2007) “Learning to Generate Dialogue: Theory, Practice, and Evaluation.” Museums and Social Issues 2(2): 165-184.

MacMillan, T. (2004) Engaging in Innovation: Towards an Integrated Science Policy. London: IPPR (Institute for Public Policy Research). URL: http://www.ippr.org.uk/research/teams/project.asp?id=995 (accessed October 2004).

Mercer, N. (2000) Words and Minds: How We Use Language to Think Together. London: Routledge.

Michael, M. (1992) “Lay Discourses of Science: Science-in-General, Science-in-Particular, and Self,” Science, Technology and Human Values 17(3): 313-33.

Michael, M. (1998) "Between Citizen and Consumer: Multiplying the Meanings of the 'Public Understanding of Science,"” Public Understanding of Science 7: 313-27.

Millar, R. and Osborne, J., eds (1998) Beyond 2000: Science Education for the Future. London: King’s College London.

Mortimer, E.F. and Scott, P.H. (2003) Meaning Making in Secondary Science Classrooms. Buckingham: Open University Press.

NMSI (2002) In the 21st Century What Role Should a Museum Play. NMSI brochure.

Osborne, J. (2000) “Science for Citizenship,” in M. Monk and J.F. Osborne (eds) Good Practice in Science Teaching: What Research Has to Say, pp. 225-40. Buckingham: Open University Press. 
Osborne, J. (2002) "Science without Literacy—A Ship without a Sail?,” Cambridge Journal of Education 32(2): 203-18.

Osborne, J., Collins, S., Ratcliffe, M., Millar, R. and Duschl, R. (2003) "What 'Ideas-about-Science' Should be Taught in School Science? A Delphi Study of the Expert Community," Journal of Research in Science Teaching 40(7): 692-720.

Parliamentary Office of Science and Technology (2001) Open Channels: Public Dialogue in Science and Technology. Report number 153, March. URL: http://www.parliament.uk/parliamentary_offices/post/pubs2001.cfm (accessed October 2004).

Parliamentary Office of Science and Technology (2006) Debating Science. Report number 260, March. URL: http:// www.parliament.uk/documents/upload/postpn260.pdf (accessed June 2006).

PEALS (2007) “Dialogue at PEALS.” URL: http://www.ncl.ac.uk/peals/dialogues/index.htm (accessed January 2007).

Ratcliffe, M. and Grace, M. (2003) Science Education for Citizenship: Teaching Socio-Scientific Issues. Maidenhead: Open University Press.

Rip, A. (1986) “Controversies as Informal Technology Assessment,” Knowledge: Creation, Diffusion, Utilization 8(2): 349-71.

Rogoff, B., Matusov, E. and White, C. (1996) "Models of Teaching and Learning: Participation in a Community of Learners," in D.R. Olson and N. Torrance (eds) The Handbook of Education and Human Development, pp. 388-414. Oxford: Blackwell.

Rogoff, B., Paradise, R., Arauz, R.M., Correa-Chavez, M. and Angelillo, C. (2003) "Firsthand Learning through Intent Participation,” Annual Review of Psychology 54: 175-203.

Royal Society (1999) Science and Society: A Response from the Royal Society to the House of Lords Science and Technology Select Committee Inquiry. URL: http://www.royalsoc.ac.uk/document.asp?tip=0\&year=1999 \&id=1170 (accessed July 2006).

Rowe, G. and Frewer, L.J. (2000) “Public Participation Methods: A Framework for Evaluation,” Science, Technology and Human Values 25(1): 3-29.

Rowe, G. and Frewer, L.J. (2004) “Evaluating Public-Participation Exercises: A Research Agenda,” Science, Technology and Human Values 29(4): 512-56.

Rowe, G. and Frewer, L.J. (2005) “A Typology of Public Engagement Mechanisms,” Science, Technology and Human Values 30(2): 251-90.

Rowe, G., Horlick-Jones, T., Walls, J. and Pidgeon, N. (2005) "Difficulties in Evaluating Public Engagement Initiatives: Reflections on an Evaluation of the UK GM Nation? Public Debate about Transgenic Crops,” Public Understanding of Science 14: 331-52.

Rowe, S.M. (2004) "Discourse in Activity and Activity as Discourse," in R. Rogers (ed.) An Introduction to Critical Discourse Analysis in Education, pp. 79-96. Mahwah, NJ: Lawrence Erlbaum Associates.

Sadler, T.D. and Zeidler, D.L. (2003) "The Morality of Socioscientific Issues: Construal and Resolution of Genetic Engineering Dilemmas,” Science Education 88: 4-27.

Sawyer, R.K. (2006) “Analyzing Collaborative Discourse,” in R.K. Sawyer (ed.) Cambridge Handbook of the Learning Sciences, pp. 187-204. New York: Cambridge University Press.

Science Museum Visitor Research Group (2004) Naked Science: Evaluation of 18 Months of Contemporary Science Dialogue Events. London: Science Museum.

Silberman, C.E. (1970) Crisis in the Classroom: The Remaking of American Education. New York: Random House.

Simonsson, E. (2006) Dana Centre Audience Research Report 2005-2006. London: Science Museum.

Spire, A. (1998) “Marc Sautet, promoteur des ‘cafés philo’, est mort,” Journal l’Humanité 4 March.

Vygotsky, L.S. (1978) Mind in Society: The Development of Higher Psychological Process. Cambridge, MA: Harvard University Press. 
Wells, G. (1999) Dialogic Inquiry: Towards a Sociocultural Practice and Theory of Education. Cambridge: Cambridge University Press.

Wynne, B. (1992a) “Public Understanding of Science Research: New Horizons or Hall of Mirrors?,” Public Understanding of Science 1: 37-43.

Wynne, B. (1992b) “Misunderstood Misunderstanding: Social Identities and Public Uptake of Science,” Public Understanding of Science 1: 281-304.

Wynne, B. (1993) “Public Uptake of Science: A Case for Institutional Reflexivity,” Public Understanding of Science 2: 321-37.

Wynne, B. (2001) “Creating Public Alienation: Expert Cultures of Risk and Ethics on GMOs,” Science as Culture 10(4): 445-81.

Wynne, B. (2002) "Risk and Environment as Legitimatory Discourses of Technology: Reflexivity Inside Out?,” Current Sociology 50(3): 459-77.

Wynne, B. (2005) “Risk as Globalising 'Democratic’ Discourse? Framing Subjects and Citizens,” in M. Leach, I. Scoones and B. Wynne (eds) Science and Citizens: Globalisation and the Challenge of Engagement, pp. 66-82. London: Zed Books.

Yearley, S. (1999) “Computer Models and the Public’s Understanding of Science: A Case-Study Analysis,” Social Studies of Science 29(6): 845-66.

Zembylas, M. (2005) “Science Education: For Citizenship and/or for Social Justice?,” Journal of Curriculum Studies 37(6): 709-22.

\section{Authors}

Sarah Davies is a Research Associate in Durham University's Institute of Hazard and Risk Research, working on a project looking at lay ethics of nanotechnology. Her PhD involved an ethnography of communication of Dana Centre events. Her research interests focus on different forms of public engagement with science. Correspondence: Department of Geography, Durham University, Science Site, South Road, Durham, DH1 3LE; email sarah. davies@durham.ac.uk.

Ellen McCallie is director of the Center for Advancement of Informal Science Education (CAISE). Her research, conducted as part of the Center for Informal Learning and Schools (CILS) at King's College London, examines how people interact and construct meaning during public engagement with science (PES) activities such as dialogue events.

Elin Simonsson is a Visitor Researcher at the Science Museum in London. Her work includes evaluation of Museum exhibitions, online resources, and programming, as well as audience advocacy. She is currently the audience advocate for the Dana Centre and is also involved in the redevelopment of a hands-on interactive gallery for children.

Jane L. Lehr is assistant professor in the Department of Ethnic Studies and Department of Women's \& Gender Studies at California Polytechnic State University. She received her Ph.D. (2006) and M.S. (2002) in Science \& Technology Studies from Virginia Polytechnic Institute and State University. Her current research explores how formal and informal education serves as a site of training for future participation by scientific and technical experts and public(s) in personal and public scientific and technical decision-making practices, with particular attention to issues of social justice and equity.

Sally Duensing is currently a visiting professor at King's College London in the Department of Education and Professional Studies. In 2000 she held the Collier Chair, a one year invited professorship in the Public Understanding of Science at the University of Bristol, UK. Prior to this, for over 20 years, she was at the Exploratorium in San Francisco. 